\title{
Studies on Strength and Related Properties of Concrete Incorporating Aggregates from Demolished Wastes: Part 2-Compressive and Flexural Strengths
}

\author{
Mmasetlhomo Tommy Gumede1, Shodolapo Oluyemi Franklin² \\ ${ }^{1}$ Norvels (Pty) Ltd T/A Engineers International, G. West Industrial, Gaborone, Botswana \\ ${ }^{2}$ Department of Civil Engineering, Faculty of Engineering and Technology, University of Botswana, Gaborone, \\ Botswana \\ Email: tgooms05@yahoo.com, franklinso@mopipi.ub.bw
}

Received 27 January 2015; accepted 16 May 2015; published 21 May 2015

Copyright (C) 2015 by authors and Scientific Research Publishing Inc.

This work is licensed under the Creative Commons Attribution International License (CC BY). http://creativecommons.org/licenses/by/4.0/

\section{(c) (7) Open Access}

\begin{abstract}
In an earlier study, a comprehensive and critical review of previous investigations into the assessment of the strength of concrete incorporating aggregates from demolished wastes was conducted and it was concluded that there was a stark absence of results from the South African subcontinent including Botswana. In the present study, recycled coarse aggregates (RCA) sourced from demolished wastes collected from a landfill site in Gaborone, Botswana was used in lieu of natural coarse aggregates for the manufacture of concrete. With reference to the natural coarse aggregate, RCA replacement levels of $0 \%, 20 \%, 40 \%, 60 \%, 80 \%$ and $100 \%$ were utilized and the results of hardened concrete tests for compressive and flexural strengths were obtained. It was found that in general the compressive and flexural strengths of the recycled aggregate concrete (RAC) decreased with increasing replacement levels of natural coarse aggregates using RCA. It was concluded that RCA could be employed as a substitute for natural aggregate in concrete only up to a certain limit or partial replacement. In this respect, it was also noted that the undesirable properties of RCA were primarily due to the quantity and quality of the adhering mortar.
\end{abstract}

\section{Keywords}

Recycled Aggregates, Natural Aggregates, Demolished Wastes, Concrete, Strength 


\section{Introduction}

The construction, repair and demolition of civil engineering infrastructures like buildings, roads and bridges, etc., place an enormous demand on the utilization of natural aggregates as well as landfills for the disposal of solid wastes. The latter quite obviously includes gravel, concrete, stone, sand, metal, wood, glass, plastic, paper, etc. This construction and demolition (CD) waste is becoming of increasing concern in advanced and developing nations worldwide for several reasons. Firstly, there is the continuous industrial development coupled with the ever increasing world population. Secondly, the consequent problem of land scarcity has resulted in the increasing unavailability of landfill space. Finally, there is the growing awareness of sustainability and environmental management in order to maintain the global balance of production and consumption, conserve the earth's scarce raw materials, reduce any negative environmental impacts and preserve the planet's ecosystem.

In the land scarce Botswana, irresponsible dumping of wastes and widespread littering has posed major environmental problems in recent years (Kgosiesele and Zhaohui [1]). Also the approach of local government in towns and municipalities has been to engage in conventional waste collection and disposal as opposed to embracing more modern waste management practices (Bolaane [2]). Even in the Republic of South Africa which is arguably more technologically developed than Botswana, Macozoma [3] has noted that a large proportion of CD waste is still disposed of by land (i.e. landfill sites, illegal dumps, backfills, etc.). In all the provinces the problem of illegal dumping is still prevalent. Innovative CD waste management practice and minimization is still in its infancy, and CD waste reuse although having great potential in metropolitan areas such as Johannesburg, Cape Town and Durban, has not been fully exploited. Macozoma [3] has argued that there is an urgent need to encourage and develop secondary construction materials markets in order to reap the environmental benefits that will accrue if modern CD waste management methods are fully embraced.

It is generally accepted that $\mathrm{CD}$ waste constitutes a major proportion of total solid waste production in the world. This fact has been succinctly stated by Oikonomou [4] who observed that in Europe for instance, the construction sector alone creates $50 \%$ of total wastes. Since the largest percentage of CD waste is concrete rubble, it seems quite logical to recycle this waste and use the resulting aggregates for concrete production or as a sub-base or base layer in pavement construction (Kumutha and Vijai [5]). Recycling is the procedure whereby the previously used material is processed to create new products; it entails the breaking, removing and crushing of existing concrete into a material with a specified size and quality. This recycled aggregate concrete (RAC) is commonly used in a variety of applications including pavements, curbs, gutters, bridge foundations, structural grade concrete and bituminous concrete (Portland Cement Association [6]).

There have been several investigations to date on the use of recycled aggregates in concrete. Prominent amongst previous researches are the studies of Katz [7], Rao et al. [8], Rakshvir and Barai [9], Wagih et al. [10], etc. A major aspect of these investigations taken together has been the study of the compressive, flexural and split tensile strengths as well as modulus of elasticity of recycled aggregate concrete as compared to natural aggregate concrete. A comprehensive summary of these studies has been presented by de Brito and Saikia [11]. It is obvious from their work that the strength and related properties of RAC compared to natural aggregate concrete are to some extent dependent on the source and type of the recycled concrete aggregate employed. Franklin and Gumede [12] in their review of previous investigations on the subject have observed that in the Southern African sub-continent including Botswana, the only studies carried out have been in respect of CD waste management practices and procedures. There appears to be a dearth of investigations on strength and related properties of recycled concrete or concrete incorporating aggregates from demolished wastes in Southern Africa in general. It is for the latter reason that the present study has been carried out. Demolished concrete wastes have been collected from the major dump or landfill sites in Gaborone the capital city of Botswana. One aim of the study has been to assess the mechanical performance of concrete made from recycled local aggregates and the viability of such concrete for possible uses in construction work. It is expected that the present work in addition to future investigations on other aspects of demolished concrete wastes would ultimately lead to the production of comprehensive guidelines in the Southern African hemisphere regarding the use of construction and demolition wastes for concrete manufacture. An end goal of the current study is to encourage sustainable construction locally, thereby conserving scarce natural resources and hence reducing any adverse environmental impacts.

The work reported in the subsequent sections is divided into several parts. Firstly, the materials used and the methods employed in respect of the design of the concrete mix, casting, manufacture and testing of the concrete specimens are described in detail. Following this, the results with reference to the slump, density of concrete as well as the compressive and flexural strengths are presented sequentially section by section, in tandem with the 
corresponding discussions, in order to make the latter more meaningful and focused. Areas of agreement or divergence from the findings of previous investigators are highlighted where necessary.

\section{Materials and Methods}

\subsection{Materials}

BOTCEM Portland cement CEM II/B-W 32.5R containing between 21\% - 35\% of fly ash with slower than average rate of hydration (Cement and Concrete Institute [13]) was utilized. Locally available river sand passing a $4.75 \mathrm{~mm}$ sieve and possessing a fineness modulus of 3.1 was employed as fine aggregate. Natural and recycled coarse aggregates of $19 \mathrm{~mm}$ maximum size were used. The natural aggregates were obtained from Kgale Quarries while the recycled concrete aggregates were extracted from waste material at the Glen Valley garden disposal site in Gaborone. Sampling was done twice in order to accumulate the target size which was more than double the actual required size. Initially a $4.5 \mathrm{~kg}$ hammer was used to break and crush some of the concrete to smaller sizes which together with some loose aggregates which had probably been crushed during demolition was put in plastic sample bags. With reference to the second sampling however, crushing and sieving took place right at the Glen Valley disposal site, in order to avoid transporting undesirable wastes and to obtain more useful material. All unwanted materials like wood, plastics, lightweight crushed concrete, dirt, etc., were removed. During sieving only material which passed through a $19 \mathrm{~mm}$ sieve and was retained on a $4.75 \mathrm{~mm}$ sieve was collected. Subsequently, all the material was gathered in $65 \mathrm{~kg}$ batches in plastic bags and labeled. The $19 \mathrm{~mm}$ maximum size recycled and natural coarse aggregates used in the study are shown in Figure 1. Clean water from the tap conforming to the requirements of water for concreting and curing was employed.

\subsection{Mix Design and Proportions}

The Portland Cement Institute (PCI) method of mix design derived from ACI Standard 211.1-81 (Owens [14]) was used to determine the quantities of the different materials needed. The selected characteristic strength was $30 \mathrm{MPa}$ at 28 days. For the mix design, parameters such as the compacted bulk density and relative density with respect to the cement, sand and aggregate were assumed or taken from the supplier's guidelines, and these provided a reasonable engineering estimate of material characteristics. The calculated mix proportions were ascertained using trial mixes; the latter were assessed for consistency and for cohesiveness. Slight adjustments were made as necessary to the mix proportions and the final selection is shown in Table 1. The control mix (CM) had proportions of 1(cement): 1.64 (fine aggregate): 2.50 (coarse aggregate), but had no recycled aggregates. Five different additional mixes were utilized to investigate the effect of adding recycled coarse aggregates (RCA) on the mechanical properties of concrete. The water-cement ratio for all the mixes was 0.5 and the slump range was $25 \mathrm{~mm}$ - $100 \mathrm{~mm}$ with moderate vibration. In mixes RC20, RC40, RC60, RC80 and RC100, the natural coarse aggregates were substituted with $20 \%, 40 \%, 60 \%, 80 \%$ and $100 \%$ crushed concrete aggregates in that order.
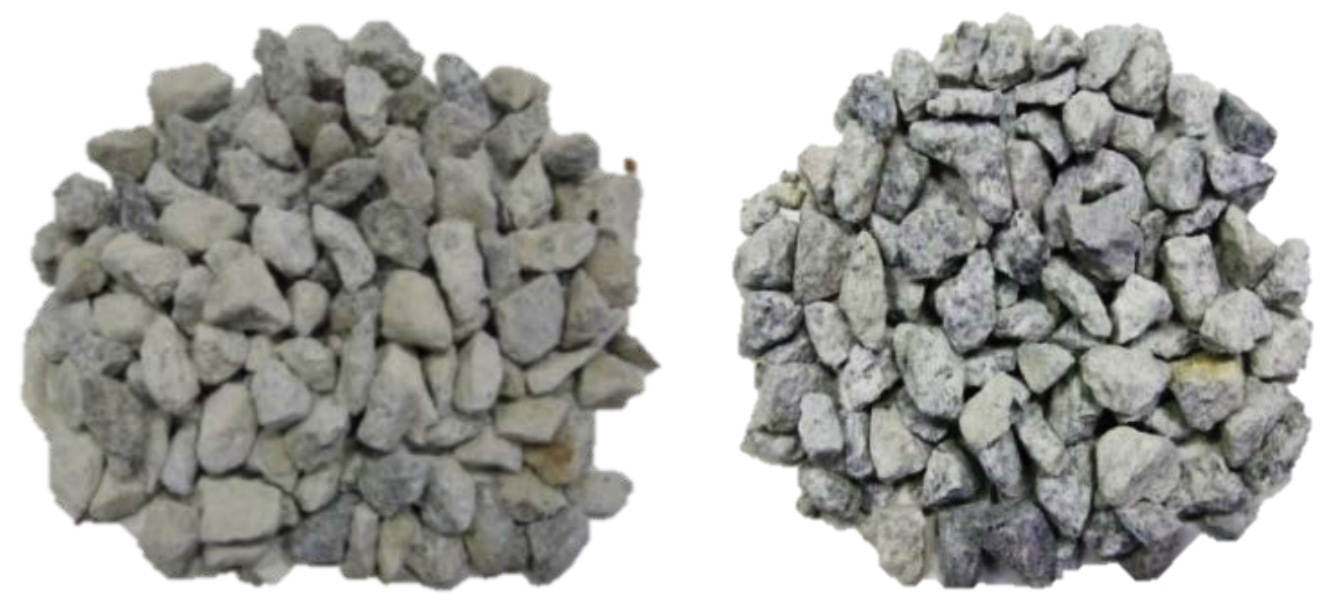

Figure 1. Batches of $19 \mathrm{~mm}$ recycled concrete and $19 \mathrm{~mm}$ natural aggregates. 
Table 1. Details of mix proportions for a $1 \mathrm{~m}^{3}$ concrete mix.

\begin{tabular}{cccccc}
\hline Specimen type & Cement $(\mathrm{kg})$ & $\begin{array}{c}\text { Natural fine } \\
\text { aggregate }(\mathrm{kg})\end{array}$ & $\begin{array}{c}\text { Natural coarse } \\
\text { aggregate }(\mathrm{kg})\end{array}$ & $\begin{array}{c}\text { Recycled coarse } \\
\text { aggregate }(\mathrm{kg})\end{array}$ & Water (kg) \\
\hline CM & 420 & 689 & 1048.80 & 0 & 210 \\
RC20 & 420 & 689 & 839.04 & 209.76 & 210 \\
RC40 & 420 & 689 & 629.28 & 419.52 & 210 \\
RC60 & 420 & 689 & 419.52 & 629.28 & 210 \\
RC80 & 420 & 689 & 209.76 & 839.04 & 210 \\
RC100 & 420 & 689 & 0 & 1048.80 & 210 \\
\hline
\end{tabular}

\subsection{Casting, Curing and Testing}

Mixing was carried out by a standard mixer which had the advantage of preventing loss of water or material. After the constituents were accurately weighed on a scale, they were loaded into the skip with half coarse, then fine aggregate, followed by cement and finally with the remaining half of the coarse aggregates. The combination was mixed until the mixture became uniform in appearance. Water was then slowly added with further mixing until the concrete was of uniform constituency. Each mix proportion was tested for slump in accordance with Method D3 in Technical Methods for Highways TMH1 [15]. For each mix, twelve $150 \mathrm{~mm}$ cubes and one beam of dimension $150 \mathrm{~mm} \times 150 \mathrm{~mm} \times 600 \mathrm{~mm}$ were cast and vibrated in three layers using steel moulds in conjunction with a vibrating table. Shortly after manufacture the cast specimens were covered by polythene sheet at ambient temperature for 24 hours. Afterwards the moulds were removed and the concrete specimens immersed in a temperature regulated water bath until they were ready for testing.

The cubes were utilized to evaluate the compressive strength of concrete at 3, 7, 14 and 28 days. However just prior to testing, the cube specimens were employed to determine the density of the concrete. The cube testing was done using a compressive testing machine with the load being applied at a constant rate until the specimen failed. The failure load was recorded and an average of three test results was taken as the compressive strength of the concrete. For the flexural strength the $150 \mathrm{~mm} \times 150 \mathrm{~mm} \times 600 \mathrm{~mm}$ concrete beams were tested at 28 days using an automatic flexural strength testing machine of $150 \mathrm{KN}$ capacity and a centre-point loading system. The load was applied at a constant rate of $0.03 \mathrm{MPa} / \mathrm{sec}$ until failure occurred. The maximum load was recorded and the flexural strength calculated. A typical beam specimen failure is shown in Figure 2.

\section{Results and Discussion}

\subsection{Slump of the Fresh Concrete}

Table 2 shows how the slump was influenced by the replacement of the natural coarse aggregate with the RCA. There was a slump reduction of $25 \%$ - 58.3\% corresponding to $20 \%$ RCA to $100 \%$ RCA replacement. Figure 3 illustrates how the slump decreases with increase in the RCA replacement level. The control mix with $0 \%$ RCA had the highest slump; there is an approximately linear decrease in slump as the RCA replacement level increases from $20 \%$ to $10 \%$. It should be noted here however that the recycled coarse aggregates were not initially saturated prior to being used, and the same water-cement ratio was maintained for the test series. Recycled coarse aggregates have a relatively greater amount of old mortar paste; with no additional water made available to cater for such mortar paste, any water introduced in the mix would be practically absorbed by the paste resulting in less water being available for the concrete mix. Consequently the concrete becomes less workable and there is hence a reduction in slump.

The above results are consistent with those noted by previous investigators. For instance, Ahmad et al. [16] reported that when the water-cement ratio of the mixture was maintained at a constant value of 0.47 throughout, the slump of mixtures with recycled aggregates decreased as the percentage of recycled fine aggregates increased. Guan [17] found that when RCA is used under saturated surface dry conditions, the mixing water need not be adjusted to achieve the desired slump. Nevertheless the marginally lower slump of RAC when compared with the reference concrete appeared to suggest that the adhering mortar on the RCA provided some resistance to flow of the concrete. Concrete made with 24 hours pre-soaked RCA achieved the desired slump. Rao et al. [8] 


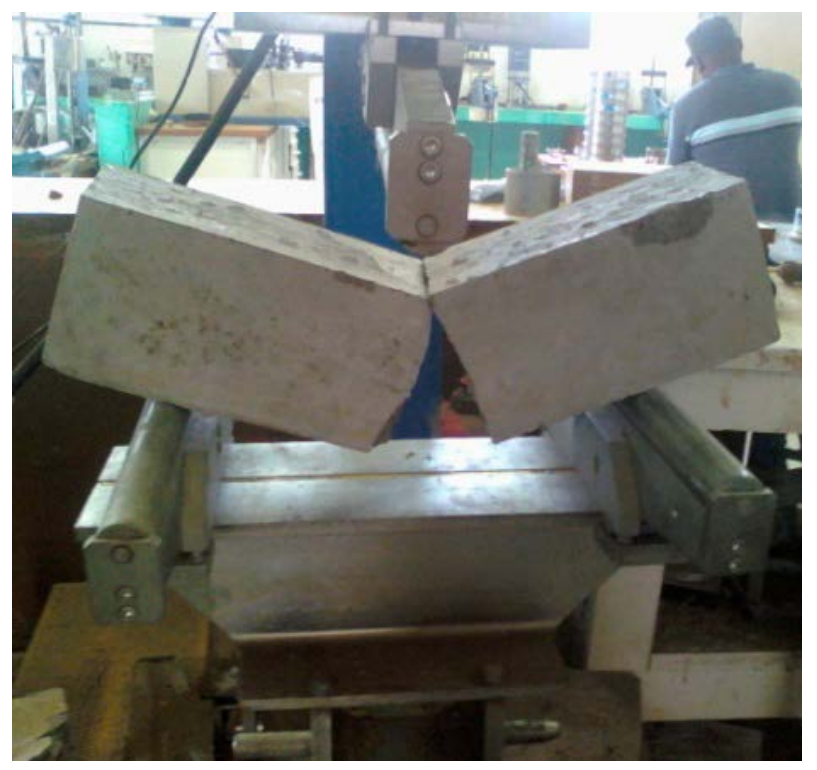

Figure 2. Typical flexural beam specimen failure.

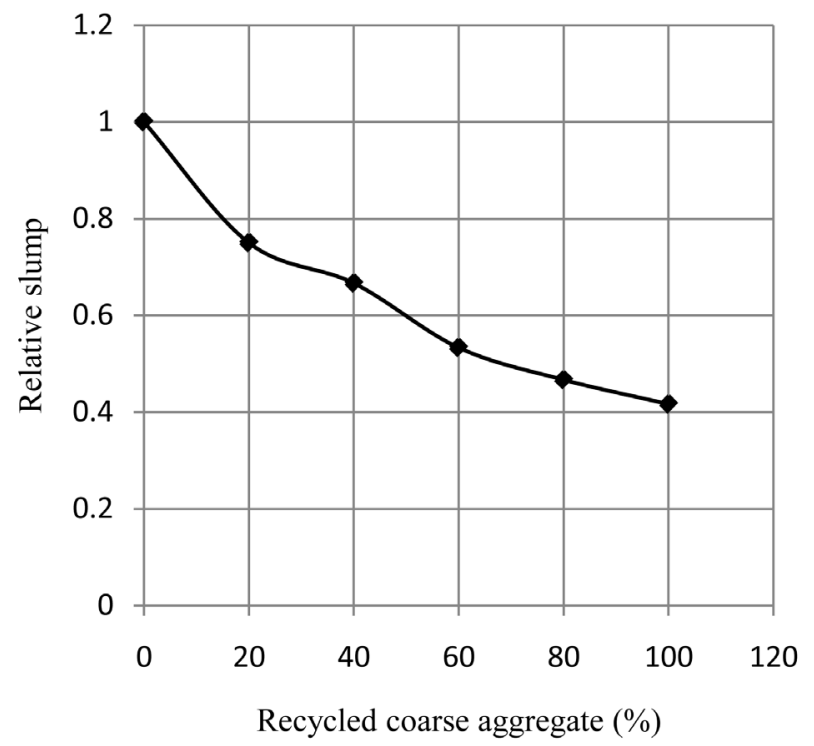

Figure 3. Slump of the recycled concrete relative to the reference concrete.

Table 2. Results of slump tests.

\begin{tabular}{ccc}
\hline Specimen type & Slump $(\mathrm{mm})$ & Reduction (\%) \\
\hline CM & 60 & 0 \\
RC20 & 45 & 25 \\
RC40 & 40 & 33.3 \\
RC60 & 32 & 46.7 \\
RC80 & 28 & 53.3 \\
RC100 & 25 & 58.3
\end{tabular}


noted that the workability of RAC for the same water content in the concrete is lower, especially when the replacement levels exceed 50\%. Masood et al. [18] reported that the workability of the concrete decreases with increase in the quantity of demolished waste. Hansen [19] opined that in actual concrete production it might be necessary to pre-soak recycled aggregates in order to avoid rapid slump loss and early setting of the fresh RAC.

\subsection{Density of Concrete}

The effect which replacement of natural coarse aggregate with RCA had on the density of concrete is presented in Table 3. It is apparent that between 3 days and 14 days, there is no consistent relationship between the density and the RCA percentage replacement. The computed densities for these days only give a clue of tolerable performance. However, for 28 days the situation radically alters; increasing replacement proportions result in a reduction of the density of the concrete.

The results are also illustrated in Figure 4. The concrete specimens with $100 \%$ replacement levels of natural coarse aggregates with RCA exhibit the highest percentage reduction in density. For example the reduction is $7.12 \%$ at $100 \%$ RCA replacement in contrast to $1.10 \%$ reduction at $20 \%$ RCA replacement. This result is almost certainly due to the higher amount of cement mortar attached to the 100\% RCA replacement concrete compared to other samples. According to Rao et al. [8], the air content of the recycled concrete at the level of $100 \%$ replacement is a little higher (4\% - 5.5\%) than concrete made with wholly natural aggregate. This increased air content can be attributed to the higher porosity of the recycled aggregate. The net effect is that concretes made with recycled aggregates have lower masses due to the higher air void content. This in turn results in lower densities when compared to concretes made with natural coarse aggregates. The trend of results shown in Figure 4 for the present study is quite similar to that observed by Kumutha and Vijai [5] in their investigations based on recycled aggregates derived from crushed concrete.

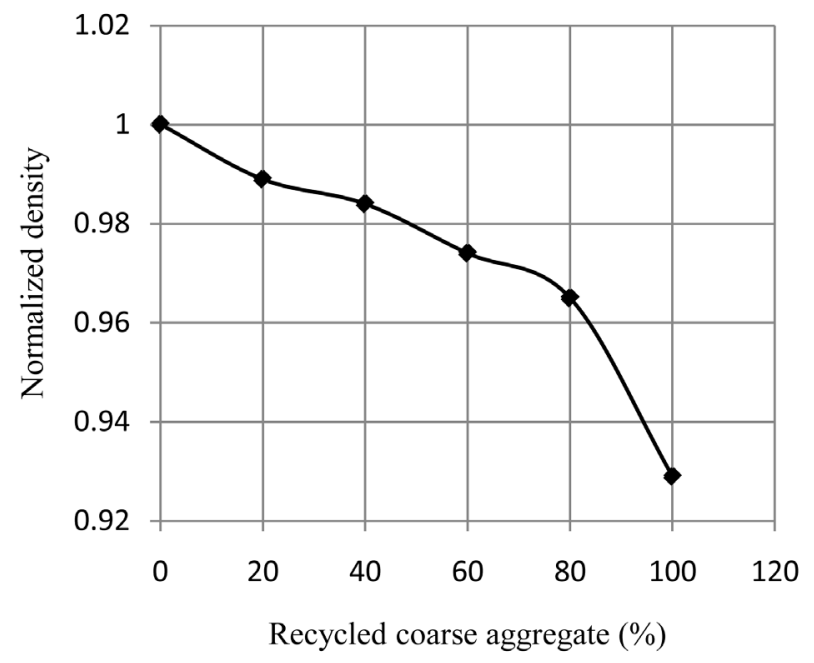

Figure 4. Density of recycled aggregate concrete at 28 days, relative to the reference concrete.

Table 3. Density test results.

\begin{tabular}{ccccc}
\hline & \multicolumn{3}{c}{ Density $\left(\mathrm{kg} / \mathrm{m}^{3}\right)$} & \\
\hline Specimen type & 3 days & 7 days & 14 days & 28 days \\
\hline CM & 2362 & 2331 & 2369 & 2374 \\
RC20 & 2331 & 2324 & 2306 & 2348 \\
RC40 & 2310 & 2326 & 2335 \\
RC60 & 2310 & 2327 & 2316 & 2313 \\
RC80 & 2331 & 2315 & 2313 & 2291 \\
RC100 & 2315 & 2307 & 2301 & 2205 \\
\hline
\end{tabular}




\subsection{Compressive Strength}

The average or mean compressive strengths for grade 30 concrete at $3,7,14$ and 28 days with different RCA replacement levels of $0 \%, 20 \%, 40 \%, 60 \%, 80 \%$ and $100 \%$ are shown in Table 4 . It is obvious that the compressive strength is affected by the level of RCA replacement of natural coarse aggregates. Interestingly, concrete of higher RCA replacement levels may produce higher compressive strengths than concrete of lower RCA percentages. For instance at 3 days, specimens of 60\% RCA and 80\% RCA have higher compressive strengths than specimens of $40 \%$ RCA. This trend continues even at 7 days. However the situation changes at 14 days, and this alteration is maintained at 28 days where for all proportions there is consistent strength reduction. It is also evident that in general, concrete with $100 \%$ RCA replacement level produces the lowest compressive strength. At 28 days the compressive strength reduction with reference to the control mix ranges between $13.7 \%-39.5 \%$ for $20 \%-100 \%$ RCA concrete in that order.

From Table 4 at 28 days, the compressive strength of the concrete specimens for $60 \%$ RCA drops by $24.0 \%$ in comparison to that of the reference concrete. Notwithstanding, its value is $32.68 \mathrm{MPa}$ which exceeds the target strength of $30 \mathrm{MPa}$. Hence it is obvious that RCA up to a level of $60 \%$ replacement could be used as a substitute for natural aggregates in concrete applications such as concrete blocks or pavements. The variation in compressive strength at 28 days with percentage RCA replacement levels is illustrated graphically in Figure 5. In fact there is an almost linear variation. The results demonstrate that the compressive strength decreases as

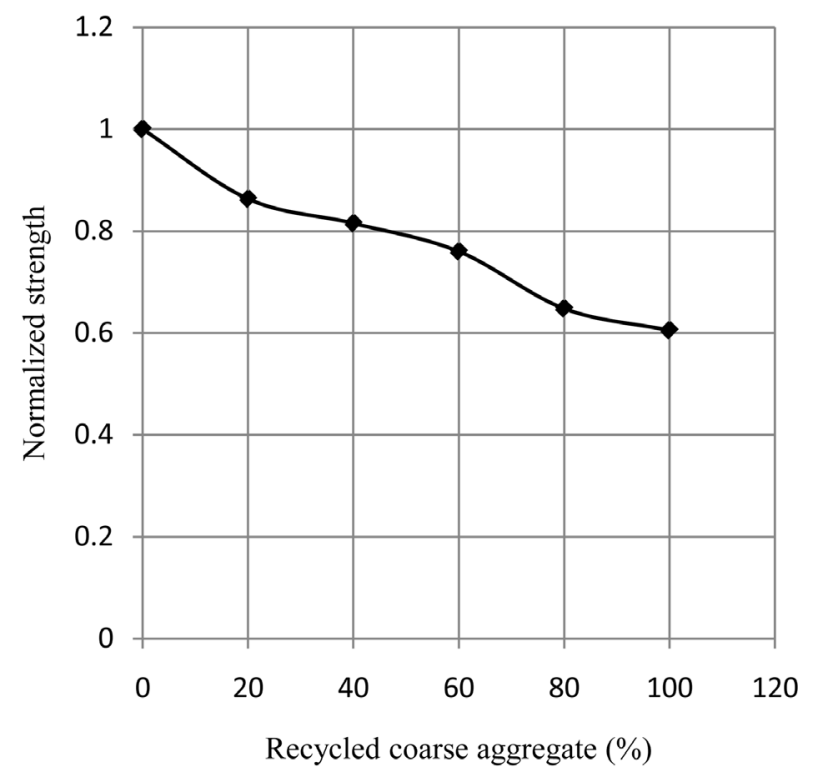

Figure 5. Compressive strength of the recycled aggregate concrete normalized to the reference concrete at age 28 days.

Table 4. Compressive strength of concrete at different days.

\begin{tabular}{|ccccc|}
\hline RCA level & \multicolumn{4}{c}{ Compressive strength (MPa) } \\
\hline$(\%)$ & 3 days & 7 days & 14 days & 28 days \\
\hline 0 & 17.91 & 28.00 & 39.04 & 43.02 \\
20 & 12.29 & 21.18 & 34.00 & 37.13 \\
40 & 10.01 & 20.38 & 32.67 & 35.04 \\
60 & 15.32 & 21.74 & 29.86 & 32.68 \\
80 & 16.19 & 20.47 & 26.81 & 27.89 \\
100 & 10.60 & 17.80 & 21.18 & 26.04 \\
\hline
\end{tabular}


the percentage of RCA increases. These findings are in agreement with those of Ahmad et al. [16] in their study on North Carolina recycled coarse and fine aggregates. They observed that the concrete strength decreases approximately in a linear fashion as the percentage replacement of natural fine aggregate with recycled fine aggregate increases. A similar trend was also reported by Kumutha and Vijai [5] who utilized crushed concrete from demolished structures as recycled coarse aggregate. Khergamwala et al. [20] who sourced for RCA by utilizing crushed concrete from laboratory wastes also reported a roughly linear decrease in compressive strength at 28 days with increase in percentage RCA replacement levels.

In the present study the shape of the RCA is generally irregular; as the RCA is broadly accepted to contain a sizeable level of old mortar paste, this would lead to the creation of a lot of voids in the concrete thus making good bond a problem during compaction unlike the case with natural coarse aggregates. Hence it can be stated that the quantity of adhering mortar has a major influence on the compressive strength of the concrete, since it can cause additional areas of weak bonds in the recycled aggregates. Rakshvir and Barai [9] have also arrived at basically the same conclusion. However some cautionary comments may be appropriate here. Studies by Ajdukiewicz and Kliszczewicz [21] suggest that in respect of bond the difference between recycled or new aggregates might not be as significant as previously espoused particularly by Hansen [22]. Consequently in view of the lack of agreement or unanimity amongst investigators in this regard, it may be prudent to advise that in the design of moderate or high strength RCA, conventional methods of concrete design may not be totally applicable. Some adjustments may be necessary in order to deal with the problem of adhering mortar, as well as issues regarding workability which had been dwelt upon earlier on during the course of the current study.

\subsection{Flexural Strength}

The values of flexural strength at 28 days for the different levels of RCA replacement are shown in Table 5 . The flexural strength for $100 \%$ RCA replacement is the lowest, while the reference concrete which had 0\% RCA replacement has the highest flexural strength. The first replacement proportion of 20\% RCA has strength differing from the control concrete by $8.2 \%$, while the maximum reduction for the test series is $48.8 \%$. It can be seen that generally even the mass of the beams reduce with RCA increase, showing that the greater the RCA content the less dense the specimens become, a situation encountered earlier on in relation to density of cube specimens. In Figure 6 the variation in flexural strength with the \% RCA replacement levels is illustrated. In general, the flexural strength decreases as the \% RCA replacement level increases. The decrease is more significant for the $100 \%$ RCA concrete. Guan [17] reported that there are two different interfacial zones (ITZ) in RCA concrete instead of one as in normal concrete, i.e., an old ITZ between the original aggregate and the adhering mortar, and a new ITZ between the recycled aggregate and the new cement paste; this makes it impossible for particles to pack well around the embedded aggregates, hence the low strength. The higher mortar content in the RCA concretes will result in weaker ITZ bonding, hence the lower flexural strength with increase in \% RCA replacement.

No attempt has been made in the present study to establish a relationship between the flexural and compressive strengths of the RCA specimens. This is on account of the limited number of tests carried out in respect of the flexural beam specimens in particular. Such an investigation however is actually worthy of pursuit. In Table 6 the ratios of the flexural strength to the cylinder strength assuming the latter's value to be 0.8 times the cube strength is shown. For the $20 \%$ RCA-100\% RCA specimens, the ratio of the flexural to the cylinder strengths are within the range $16 \%$ - 23\% quoted by Katz [7]; on average the ratios are in fair agreement with the equation

Table 5. Flexural strength test results.

\begin{tabular}{cccc}
\hline RCA (\%) & Mass (kg.) & Maximum load (KN) & Flexural strength (MPa) \\
\hline 0 & 31.965 & 31.144 & 6.23 \\
20 & 31.465 & 28.611 & 5.72 \\
40 & 31.190 & 29.979 & 6.00 \\
60 & 31.310 & 21.143 & 4.23 \\
80 & 31.050 & 19.334 & 3.87 \\
100 & 30.840 & 15.946 & 3.19 \\
\hline
\end{tabular}




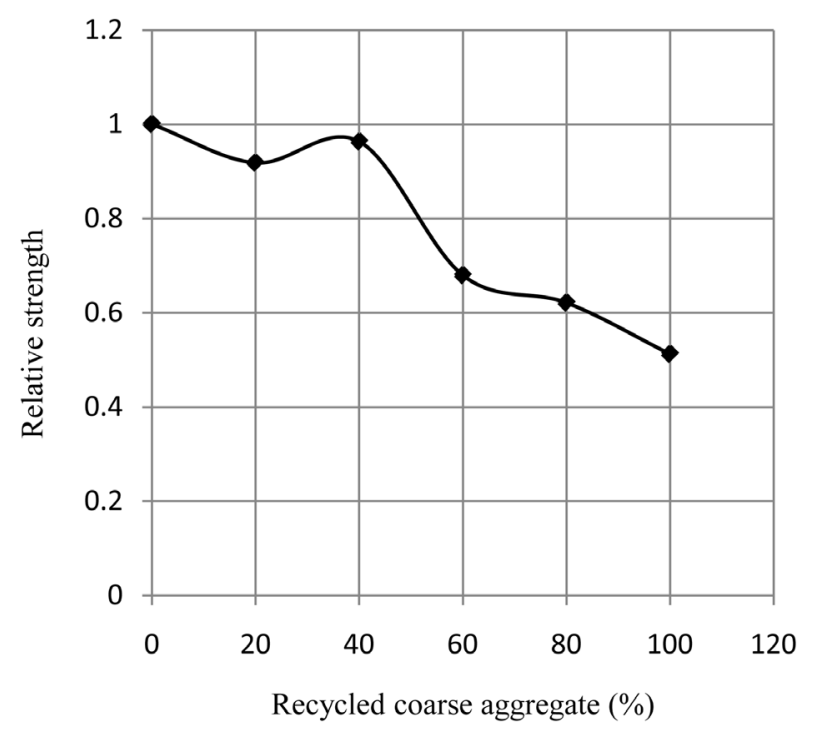

Figure 6. Flexural strength of the recycled aggregate concrete relative to the reference concrete at age 28 days.

Table 6. Approximations for relationship between flexural and compressive strengths.

\begin{tabular}{|c|c|c|c|c|}
\hline RCA (\%) & Compressive strength, $\mathrm{f}_{\mathrm{cu}}(\mathrm{MPa})$ & Flexural strength, $\mathrm{f}_{\mathrm{c}}{ }_{\mathrm{c}}(\mathrm{MPa})$ & Ratio $\frac{\mathrm{f}_{\mathrm{r}}^{\prime}}{0.8 \mathrm{f}_{\mathrm{Cu}}}$ & Ratio $\frac{\mathrm{f}_{\mathrm{r}}^{\prime}}{\sqrt{0.8 \mathrm{f}_{\mathrm{Cu}}}}$ \\
\hline 0 & 43.02 & 6.23 & 0.181 & 1.062 \\
\hline 20 & 37.13 & 5.72 & 0.193 & 1.050 \\
\hline 40 & 35.04 & 6.00 & 0.214 & 1.133 \\
\hline 60 & 32.68 & 4.23 & 0.162 & 0.827 \\
\hline 80 & 27.89 & 3.87 & 0.173 & 0.819 \\
\hline 100 & 26.04 & 3.19 & 0.153 & 0.699 \\
\hline \multicolumn{3}{|c|}{ Average for $20 \%-100 \%$ RCA } & 0.179 & $0.906^{\mathrm{a}}$ \\
\hline \multicolumn{3}{|c|}{ Standard deviation for $20 \%-100 \%$ RCA } & 0.025 & 0.180 \\
\hline
\end{tabular}

a. ACI 363R recommended equation is $f_{r}^{\prime}=0.94 \sqrt{f_{c}^{\prime}}$, where $f_{c}^{\prime}$ is the cylinder strength (Katz [7]).

recommended by ACI 363R for concrete of compressive strength in the range of 21 - $83 \mathrm{MPa}$, as listed by the same investigator. Surprisingly Katz [7] opined that the flexural strength values for his ordinary Portland cement recycled concrete were relatively high in contrast to the recommendations of ACI 363R. On the other hand, Rakshvir and Barai [9] have recorded more modest values of flexural strengths. They found that the flexural strength of recycled gravel aggregate concrete was up to $10 \%$ lower than that of natural aggregate concrete for the range $0 \%$ - $50 \%$ replacement. Possibly the source and type of the RCA does have an influence here.

\section{Conclusion}

The study described herein is a part of a continuing investigation at the University of Botswana on the assessment of the strength of concrete incorporating aggregates using locally sourced demolished wastes. The focus of the present work is the compressive and flexural strengths of recycled aggregate concretes. From the investigations carried out, a number of conclusions may be deduced. Firstly in recycled aggregate concretes the adhering mortar in the RCA can have a significant effect on the performance of the concrete. More particularly, the quantity and quality of the adhering mortar can profoundly affect the workability of the fresh concrete mix as well as 
the strength of the hardened concrete. Secondly as a consequence, in the manufacture of the fresh concrete, it may be necessary to pre-soak the RCA in order to avoid rapid slump loss and early setting of the fresh concrete. Thirdly, with increasing RCA replacement of natural coarse aggregate in the concrete mix, the density in addition to the compressive and flexural strengths of the concrete is progressively reduced in relation to the reference concrete. Finally in respect of the tests conducted in the study, it is observed that RCA up to a level of $60 \%$ replacement of the natural coarse aggregate may be utilized in infrastructural applications like concrete pavements and blocks.

\section{References}

[1] Kgosiesele, E. and Zhaohui, L. (2010) An Evaluation of Waste Management in Botswana: Achievements and Challenges. Journal of American Sciences, 6, 144-150.

[2] Bolaane, B. (2006) Constraints to Promoting People Centred Approaches in Recycling. Habitat International, 30, 731740. http://dx.doi.org/10.1016/j.habitatint.2005.10.002

[3] Macozoma, D.S. (2006) Developing a Self-Sustaining Secondary Construction Materials Market in South Africa. Master of Science Dissertation, University of the Witwatersrand, Johannesburg.

[4] Oikonomou, N.D. (2005) Recycled Concrete Aggregates. Cement and Concrete Composites, 27, 315-318. http://dx.doi.org/10.1016/j.cemconcomp.2004.02.020

[5] Kumutha, R. and Vijai, K. (2010) Strength of Concrete Incorporating Aggregates Recycled from Demolition Waste. ARPN Journal of Engineering and Applied Sciences, 5, 64-71.

[6] Portland Cement Association (2011) Recycled Aggregates. Materials Concrete Technology. http://cement.org/tech/index.asp

[7] Katz, A. (2003) Properties of Concrete Made with Recycled Aggregate from Partially Hydrated Old Concrete. Cement and Concrete Research, 33, 703-711. http://dx.doi.org/10.1016/S0008-8846(02)01033-5

[8] Rao, A., Jha, K.N. and Misra, S. (2007) Use of Aggregates from Recycled Construction and Demolition Waste Concrete. Resources, Conservation and Recycling, 50, 71-81. http://dx.doi.org/10.1016/j.resconrec.2006.05.010

[9] Rakshvir, M. and Barai, S.V. (2006) Studies on Recycled Aggregate-Based Concrete. Waste Management Research, 24, 225-233. http://dx.doi.org/10.1177/0734242X06064820

[10] Wagih, A.M., El-Karmoty, H.Z., Ebid, M. and Okba, S.H. (2012) Recycled Construction and Demolition Waste as Aggregate for Structural Concrete. HBRC Journal, 9, 193-200. http://dx.doi.org/10.1016/j.hbrcj.2013.08.007

[11] de Brito, J. and Saikia, N. (2013) Recycled Aggregate in Concrete: Use of Industrial, Construction and Demolition Waste. Green Energy and Technology, Springer-Verlag, London. http://dx.doi.org/10.1007/978-1-4471-4540-0

[12] Franklin, S.O. and Gumede, M.T. (2014) Studies on Strength and Related Properties of Concrete Incorporating Aggregates from Demolished Wastes: Part 1-A Global Perspective. Open Journal of Civil Engineering, 4, 311-317. http://dx.doi.org/10.4236/ojce.2014.44026

[13] Cement and Concrete Institute South Africa (Undated) Cementitious Materials for Concrete—Standards, Selection and Properties. http://www.afrisam.co.za/media/13704/Cementitious materials for concrete.pdf

[14] Owens, G. (2009) Fulton’s Concrete Technology. 9th Edition, Cement and Concrete Institute, Midrand.

[15] National Institute for Transport and Road Research (1986) Standard Methods of Testing Road Construction Materials. Technical Methods for Highways (TMH) 1, 2nd Edition, CSIR, Pretoria.

[16] Ahmad, S.H., Fisher, D.G. and Sackett, K.W. (1996) Properties of Concrete Made with North Carolina Recycled Coarse and Fine Aggregates. Centre for Transportation Engineering Studies, North Carolina State University, Raleigh.

[17] Guan, J.L.L. (2011) Effects of Recycled Aggregates on Concrete Properties. Master of Engineering Thesis, National University of Singapore, Singapore.

[18] Massod, A., Ahmad, T., Arif, M. and Mahdi, F. (2002) Waste Management Strategies of Concrete. Environmental Engineering and Policy, 3, 15-18. http://dx.doi.org/10.1007/s100220100034

[19] Hansen, T.C. (1992) Recycling of Demolished Concrete and Masonry. Report of Technical Committee 37-DRC Demolition and Reuse of Concrete. RILEM, E \& FN Spon, London.

[20] Khergamwala, P.C., Singh, J. and Kumar, R. (2013) Effect of Recycled Coarse Aggregates on Characteristic Strength of Different Grades of Concrete. International Journal of Civil Engineering and Technology, 4, 186-192.

[21] Ajdukiewicz, A. and Kliszczewicz, A. (2002) Influence of Recycled Aggregates on Mechanical Properties of HS/HPC. Cement and Concrete Composites, 24, 269-279. http://dx.doi.org/10.1016/S0958-9465(01)00012-9

[22] Hansen, T.C. (1986) Recycled Aggregates and Recycled Aggregate Concrete Second State-of-the-Art Report Developments 1945-1985. Materials and Structures, 19, 201-246. http://dx.doi.org/10.1007/BF02472036 